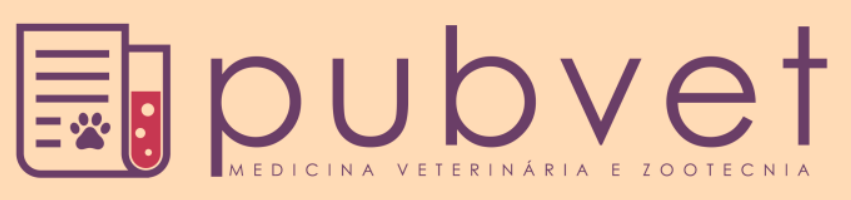

https://doi.org/10.22256/pubvet.v12n1a11.1-5

\title{
Sustentabilidade no sistema de produção de leite em pequenas propriedades rurais em Bragança - Pará
}

\author{
Claudina Rita de Souza Pires ${ }^{\bullet} 1 *$, Clarice da Silva Costa ${ }^{\bullet}$, Tamise Loena Assunção de \\ Melo $^{3}$, Maria Audileia da Silva Teixeira ${ }^{4}{ }^{\circ}$, Ana Estelita Nascimento de Carvalho ${ }^{\circ}$ \\ ${ }^{I}$ Professora do Instituição Federal de Ciência, Educação e Tecnologia do Pará. Bragança - PA Brasil. \\ ${ }^{2}$ Estudante do Curso Tecnologia em Agroecologia, Instituição Federal de Ciência, Educação e Tecnologia do Pará, Brasil. \\ ${ }^{3}$ Estudante do Curso Técnico em Agropecuária; Instituição Federal de Ciência, Educação e Tecnologia do Pará, Brasil. \\ ${ }^{4}$ Estudantes de pós-graduação da Universidade Federal do Pará - Campus Castanhal, Brasil. \\ *Autor para correspondência,E-mail: claudina.pires@ifpa.edu.br
}

RESUMO. A atividade leiteira tem um importante papel na sustentabilidade das unidades de base familiar, tanto no autoconsumo como na geração de renda, no entanto é necessário que seja economicamente viável para evitar a saída do homem do campo. Os objetivos deste trabalho foram fazer um acompanhamento técnico em propriedades leiteiras com intuito de maximizar a produção de leite a pasto, melhorar a qualidade do leite através da adoção de Boas Práticas de Produção e tornar os sistemas de produção de leite sustentável. Foi aplicado um questionário com intuito de obter informações sobre infraestrutura da unidade produtora, manejo dos animais e traçar o perfil dos produtores. Além disso, as alunas vivenciaram a rotina da propriedade desde a ordenha das vacas até a comercialização do leite. Como resultados alcançados têm-se a capacitação dos produtores rurais em adquirir animais com aptidão leiteira, manejo nutricional e sanitário adequado e adoção de boas práticas de produção de leite. Um trabalho sobre a sustentabilidade do sistema de produção leiteiro no município de Bragança-PA é bastante relevante, devido à falta de tecnologia e aplicação de manejos impróprios, resultando em produtos lácteos com baixo valor comercial e sem qualidade.

Palavras chave: leite, pequeno produtor, tecnologia

\section{Sustainability in milk production system in small rural properties in Bragança-Pará}

ABSTRAC. The dairy activity has an important role in the sustainability of family-based units, both self - consumption and income generation; however it must be economically viable to avoid the men leaving the countryside. The aim of this work were to make a systemic technical monitoring in dairy farms, making the production systems of sustainable milk, reducing costs and maximizing milk production at pasture, improving the quality of milk and adding income to farmers through methods and technologies used in milk production. As a result has the ability of rural producer to acquire animals with milk aptitude acclimated to the tropical climate, adequate nutrition and health managements and adoption of best practices in milk production. For this reason study the sustainability of the dairy production system in the county of Bragança city is quite relevant because of the lack of technology and application of improper handlings, resulting in dairy products with low commercial value and without quality.

Keywords: milk, small producer, tecnology 


\title{
Sostenibilidad del sistema de producción de leche en pequeñas propiedades rurales de Bragança-Pará
}

\begin{abstract}
RESUMEN. La actividad lechera tiene un importante papel en la sostenibilidad de las unidades de base familiar, tanto en el autoconsumo y en la generación de ingresos, sin embargo es necesario que sea económicamente viable para evitar la salida del hombre del campo. Los objetivos de este trabajo fueron hacer un seguimiento técnico en las propiedades lecheras con el objetivo de maximizar la producción de leche a pasto, mejorar la calidad de la leche a través de la adopción de Buenas Prácticas de Producción y hacer que los sistemas de producción de leche sean sostenibles. Se aplicó un cuestionario con el fin de obtener informaciones sobre infraestructura de la unidad productora, manejo de los animales y trazar el perfil de los productores. Además, las alumnas vivenciaron la rutina de la propiedad desde el ordeño de las vacas hasta la comercialización de la leche. Como resultados alcanzados se obtuvo el conocimiento de los productores rurales en adquirir animales con aptitud lechera, adecuado manejo nutricional y sanitario y adopción de buenas prácticas de producción de leche. Un trabajo sobre la sostenibilidad del sistema de producción de leche en el municipio de Bragança-PA es bastante relevante debido a la falta de tecnología y aplicación de inadecuados manejos, resultando en productos lácteos con bajo valor comercial y sin calidad.
\end{abstract}

Palabras clave: leche, pequeño productor, tecnología

\section{Introdução}

O município de Bragança está localizado a margem esquerda do rio Caeté, pertence à mesorregião do nordeste paraense. A sua economia é baseada na agricultura de autoconsumo (feijão, malva, mandioca, milho e cana de açúcar), pesca e pecuária de corte e de leite. A produção leiteira anual é próxima de 179.000 mil litros. A maior parte da produção de leite é obtida por produtores rurais voltados a agricultura familiar (ANUALPEC, 2017).

A pecuária de leite é uma das principais atividades desenvolvidas entre os agricultores familiares. Nas regiões Sul e Centro-Oeste a pecuária leiteira é bastante representativa correspondendo a $61 \%$. Nas regiões Norte e Nordeste esse valor é menor, aproximadamente 24\% (Guanziroli \& Cardim, 2000).

Por falta de organização, capital, informações e aplicação de manejos inadequados, os produtores familiares são aqueles que correm o maior risco de exclusão do setor leiteiro. Outro fator que deve ser levado em consideração é a qualidade do leite, devido à implantação da Instrução Normativa 62, que regulamenta os parâmetros de qualidade exigidos na produção e transporte deste produto. Os pequenos produtores vêm sentindo estas transformações de forma mais intensa, por terem maior dificuldade financeira para se adequar às mudanças (Souza et al., 2013). Além disso, um dos procedimentos necessário para reduzir o número de microrganismos da matéria prima, melhorar a sanidade das glândulas mamárias dos animais e aumentar o tempo de prateleira de produtos lácteos é a adoção das Boas Práticas de Produção de leite (BPP) (Leite Júnior et al., 2011). Também para otimizar a produção de leite de pequenos produtores é necessário mudar o olhar sobre a sustentabilidade da agricultura familiar. As ações coletivas e o desenvolvimento de instituições apropriadas que visem reduzir custos de transação e que forneçam um melhor acesso às tecnologias e aos mercados de insumos e produtos favorecem o crescimento dos pequenos produtores (Stoffel et al., 2014).

O objetivo desse trabalho foi tornar o sistema de produção de leite do município de Bragança PA sustentável com aplicação de tecnologia e melhoria na sua qualidade através da adoção de Boas Práticas de Produção (BPP).

\section{Material e Métodos}

Este trabalho foi realizado em três pequenas propriedades rurais no município de Bragança Pará, as quais foram selecionadas pelas informações obtidas pela EMATER (Empresa de Assistência Técnica e Extensão Rural), com o consentimento dos produtores rurais para a execução deste projeto. Assim foi possível traçar o perfil da produção leiteira local, quanto aos aspectos de produção como condições das instalações e características de manejo. Para 
caracterizar a atividade leiteira em unidades familiares, considerou-se rebanho, produção de leite, alimentação, sanidade e reprodução animal. Também foi levada em consideração, a mão de obra utilizada na propriedade, tecnologia empregada, diversificação das atividades desenvolvidas e a renda obtida. A pesquisa apresentou uma característica descritiva com abordagem metodológica quantitativa.

Durante as visitas as unidades produtoras foram aplicadas questionários aos proprietários para obtenção de dados referentes aos manejos alimentar, reprodutivo e sanitário, sistema de criação, ocorrência de doenças, cuidados higiênicos na ordenha e as técnicas sanitárias usadas na comercialização do leite.

Foram elaboradas planilhas para acompanhamento sanitário, reprodutivo do rebanho e de custos e receitas. Assim os produtores conseguiam ter controle da produção de leite em suas propriedades. O manejo sanitário foi através de métodos preventivos, curativos e calendário zoosanitário, que incluiu vacinação contra as principais doenças infecto - contagiosas (febre aftosa, brucelose, raiva, botulismo e carbúnculo sintomático) e programa de controle de mastite. Para controle e combate a carrapatos foram utilizados métodos alternativos como $\mathrm{Nim}$ indiano (Azadirachta indica).

Sobre o manejo alimentar foi adotado tempo de pastejo que atendesse as necessidades nutricionais dos animais e maior produção de leite, mantendo o pastejo a campo com gramínea Brachiaria brizantha $c v$. Marandu e implantação de banco de proteína como o uso de leguminosa Estilosante Campo Grande (Stylosanthes capitata/S.macrocephala), suplementação volumosa, mineral e aproveitamento de subprodutos agrícolas disponíveis nas propriedades, tais como: casca de mandioca (Manihot esculenta Crantz), buriti (Mauritia flexuosa), murumuru (Astrocaryum murumuru), entre outros.

Para avaliar a qualidade do leite, foram aplicadas as BPP (Boas Práticas de Produção) do leite e um sistema de ordenha higiênica para pequenos produtores com procedimentos que vão desde lavagem e secagem de tetas, filtragem do leite e higienização dos equipamentos utilizados. Dentre as ações importantes para diminuir a contaminação nas propriedades, destacam-se: higienização dos utensílios (latões e baldes) utilizando detergente neutro; limpeza das tetas das vacas em lactação (imersão dos tetos na solução desinfetante direto com iodo e depois secar os tetos com papel toalha); lavar as mãos e realizar o teste de mastite antes da ordenha, o que incluiu a retirada dos três primeiros jatos de leite de cada teta na caneca de fundo preto telada. Após a realização da ordenha os produtores colocavam as vacas em lactação para comer no cocho, ficavam em pé por uns quinze minutos para que o canal do esfíncter mamário fechasse impedindo a penetração de microrganismos causadores de mastite.

As amostras de leite foram colhidas em duas etapas, primeira antes da introdução da BPP de leite e a segunda após a implantação das boas práticas com intuito de comparar a eficiência deste procedimento higiênico sanitário. Tais amostras foram colhidas em saco plástico estéril de um litro para cada propriedade, após serem colocadas nos latões, quando então foram acondicionadas em recipientes isotérmicos com gelo e encaminhadas para o laboratório de microbiologia da UFPA (Universidade Federal do Pará) Campus de Castanhal.

As análises foram realizadas seis horas após as colheitas. Para contagem de mesófilos e coliformes fecais, foram realizadas as análises de CBT (Contagem Bacterianas Totais). Utilizou-se ágar, Lauril, verde brilhante, EC (Escherichia coli), conforme orientações do fabricante.

\section{Resultados e Discussão}

Os resultados obtidos neste trabalho compreendem desde a capacitação dos produtores rurais referente à seleção da raça bovina leiteira mais adequada para região, manejo nutricional, reprodutivo e sanitário eficiente, implantação das Boas Práticas de Produção de leite; emprego de técnicas e higienização na obtenção, transporte e conservação do leite, garantindo um produto de melhor qualidade e com maior tempo de conservação. A adoção de práticas simples realizada durante ordenha manual resulta em significativa melhora da qualidade do leite, sem agregar custos ao produto final. Sobre o melhoramento genético ocorrerão em longo prazo, no entanto foram repassados aos produtores orientações para aquisição de animais de boas características zootécnicas e melhor potencialidade leiteira.

O uso de planilhas de controle zootécnico, reprodutivo e econômico serviu para identificação dos animais e também para melhorar o padrão 
genético do rebanho. De acordo com as observações de Tupy et al. (2006), o uso de instrumentos de controle gerencial, tais como planilhas de controle e de análise de custo de produção de leite têm possibilitado tornar rentável a atividade leiteira nas pequenas propriedades familiares e transformá-las em atividade fixadora do homem no campo.

As Boas Práticas de Produção diminuem a alta presença de microrganismos encontrados no leite, considerando que a presença de microrganismos mesófilos e coliformes em grande número é indicador de má qualidade do leite e manipulação higiênica inadequada. Após a aplicação das BPP de leite nas propriedades, o resultado das análises de CBT (Contagem Bacteriana Total), mostrou-se que na propriedade 1 obteve-se $3,35 \times 10^{5}$ UFC (Unidade Formadora de Colônias), propriedade 2 $\left(2,25 \times 10^{4}\right.$ UFC) e propriedade $3\left(5,1 \times 10^{4}\right.$ UFC), a presença de microrganismos existentes no produto está dentro dos padrões estabelecidos.

Os resultados obtidos de Coliformes foram muitos significantes tendo uma redução de 99,6\% na propriedade 1 ; não houve alteração na propriedade 2 e $74,5 \%$ na propriedade 3 . Esta redução é importante, pois estes microrganismos são os principais causadores de mastite ambiental e contagiosa no rebanho leiteiro (Santos \& Fonseca, 2007). Segundo Santana et al. (2001), a incorporação de microrganismos aeróbios mesófilos ao leite pelo teto mal higienizado é de $86 \%$.

Um dos caminhos para o aumento da produção de leite nas propriedades estudadas, sem que ampliem suas áreas de pastagens seria utilização de fertilizantes, leguminosas e manejo adequado de pastagens. É importante mencionar que a produtividade está voltada diretamente ao potencial da forrageira e sua adaptabilidade. Os proprietários usavam como fonte de alimentação predominante para o seu rebanho, o capim braquiarão (Brachiaria brizantha $c v$ Marandu), onde este é de alta resistência às cigarrinhas das pastagens, além de tolerar solos arenosos e argilosos. Outra variedade encontrada em menor quantidade foi à gramínea Panicum maximum $\mathrm{cv}$ Massai, a qual dispõe de raízes profundas que captam água e nutrientes com facilidade e se adaptam às condições adversas do solo, como a compactação, alta acidez, baixa fertilidade etc. Além disso, é uma gramínea precoce que tem boa aceitação por bovinos; e gramíneas do gênero Panicum maximum cv Mombaça, o qual requer solos de textura leve, média à alta fertilidade além de produzir muita massa e ser rico em proteína bruta.

Como alimentação alternativa fornecia cana triturada na forrageira, utilizada durante o período mais seco, torta de dendê e capim canarana (Echinochloa spectabile).

As propriedades possuíam muitas plantas invasoras que são específicas de solo degradados como: malva e vassorinha (Sida rhombifolia Linn), lacre (Vismia Guianensis) e tucum (Artrocaryum chambira Burret), sendo este último de extrema preocupação em fazendas leiteiras, pois por conter espinhos poderá vir a causar danos no úbere dos animais. Estes fatores ocorrem devido à alta densidade de animais comprometendo o suporte forrageiro.

As três propriedades estudadas pouco divergiam quanto à fertilidade e textura do solo, sendo constatados solos de textura leve, arenoso, rico em matéria orgânica com enriquecimento natural (raio, urina e chuva). De acordo com o resultado das análises de solo, obteve-se $\mathrm{pH}$ em média 4,5, fósforo abaixo de $10 \mathrm{ppm}, \mathrm{K}$ abaixo de $60 \mathrm{ppm}, \mathrm{Ca}$ e $\mathrm{Mg}$ maior que $2 \mathrm{mE}, \mathrm{Al}$ abaixo de $1 \mathrm{mE}$, matéria orgânica excelente, acima de $10 \%$. Daí a necessidade de incorporar fertilizantes para aumentar a produtividade.

$\mathrm{O}$ adubo recomendado foi o fosfato natural (ARAD, antifosfato ou Marrocos) e potássio devido à baixa concentração destes macros elementos em algumas unidades produtoras, a aplicação deve ser feita após a gradagem no fim do verão. Caso a pastagem esteja consolidada e com pouca incidência de plantas invasoras, tais elementos deverão ser incorporados ao solo somente no início das chuvas e após carga pesada e rápida do gado pelos piquetes. No entanto, quando há dominância de plantas espontâneas deverá ser feito uma gradagem antes das chuvas, outra após as primeiras, em seguida replantio e adubação simultaneamente.

\section{Considerações Finais}

Mesmo com todas as dificuldades encontradas, os pequenos produtores familiares do município de Bragança - Pará, acreditam na viabilidade da atividade leiteira na região, através do emprego de tecnologia e técnicas higiênico-sanitárias na produção de leite.

A transferência de tecnologia, a intensificação de forma sustentável e o planejamento de ações 
empregado visam melhor produtividade, lucratividade e rentabilidade, permitem o melhor uso da terra, evitando, assim, o êxodo rural. Desta forma, medidas práticas como neste caso deveriam ser recomendas em várias regiões do Brasil.

\section{Agradecimentos}

A PROEXT (Pró-reitoria de Extensão) pelo incentivo financeiro no desenvolvimento deste trabalho.

A UFPA (Universidade Federal do Pará) Campus Castanhal por ceder o laboratório de microbiologia para a realização das análises microbiológicas de leite.

Ao Engenheiro Agrônomo, José de Ribamar Macatrão Pires, pela valiosa colaboração neste estudo.

Aos produtores rurais por participarem com afinco no desenvolvimento desta pesquisa.

\section{Referências Bibliográficas}

ANUALPEC. 2017. Anuário da Pecuária Brasileira, 20th edn. Instituto FNP, São Paulo, SP, Brasil.

Guanziroli, C. \& Cardim, S. E. C. S. 2000. Novo retrato da agricultura familiar: o Brasil redescoberto. INCRA, Brasília.

Leite Júnior, B. R. C. L., Oliveira, P. M., Martins, M. L., Oliveira, P. C. L., Martins, E. M. F. \& Souza, G. H. 2011. Aplicação das boas práticas agropecuárias no processo de ordenha em uma propriedade rural do município de Rio Pomba, Minas Gerais. Revista do Instituto de Laticínios Cândido Tostes, 66, 31-39.
Santana, E. H. W., Beloti, V., Barros, M. d. A. F., Moraes, L. B., Gusmão, V. V. \& Pereira, M. S. 2001. Contaminação do leite em diferentes pontos do processo de produção: I. Microrganismos aeróbios mesófilos e psicrotróficos. Semina: Ciências Agrárias, 22, 145-154.

Santos, M.V. \& Fonseca, L.F.L. 2007. Estratégias para controle de mastite e melhoria da qualidade do leite. São Paulo: Manole.

Souza, J. B. L., Alves, A. F. \& Culti, M. N. 2013. A pecuária leiteira e o risco de exclusão nos municípios de Peabiru e Quinta do Sol. Interações, 14, 203-211.

Stoffel, J. A., Colognese, S. A. \& Silva, R. N. B. 2014. A sustentabilidade na agricultura familiar e as formas de organização produtivas em contextos locais. Tempo da Ciência, 21, 5367.

Tupy, O., Primavesi, O. \& Camargo, A. C. 2006. Avaliação dos impactos econômicos, sociais e ambientais de tecnologias da Embrapa Pecuária Sudeste. 4. Técnicas de produção intensiva aplicadas a propriedades familiares produtoras de leite. Embrapa Pecuária Sudeste.

Article History:

Received 2 September 2017

Accepted 10 October 2017

Available online 22 November 2017

License information: This is an open-access article distributed under the terms of the Creative Commons Attribution License 4.0, which permits unrestricted use, distribution, and reproduction in any medium, provided the original work is properly cited. 